\title{
A model to predict the beginning of the pollen season
}

Toldam-Andersen, Torben Bo

Published in:

Grana

DOI:

$10.1080 / 00173139109427810$

Publication date:

1991

Document version

Publisher's PDF, also known as Version of record

Citation for published version (APA):

Toldam-Andersen, T. B. (1991). A model to predict the beginning of the pollen season. Grana, 30, $269-275$. https://doi.org/10.1080/00173139109427810 
This article was downloaded by: [Copenhagen University Library]

On: 17 February 2015, At: 08:44

Publisher: Taylor \& Francis

Informa Ltd Registered in England and Wales Registered Number: 1072954 Registered

office: Mortimer House, 37-41 Mortimer Street, London W1T 3J H, UK

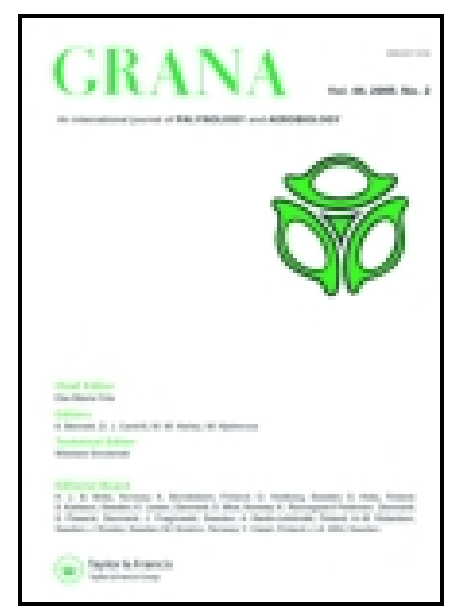

\title{
Grana
}

Publication details, including instructions for authors and subscription information:

http:// www. tandfonline.com/ loi/ sgra20

\section{A model to predict the beginning of the pollen season}

\author{
Torben B. Andersen ${ }^{\text {a }}$ \\ a Institute of Agricultural Sciences, Section of Horticulture, Royal \\ Veterinary and Agricultural University, Bülowsvej 13, DK-1870, \\ Frederiksberg C, Denmark \\ Published online: 01 Sep 2009.
}

To cite this article: Torben B. Andersen (1991) A model to predict the beginning of the pollen season, Grana, 30:1, 269-275, DOI: 10.1080/00173139109427810

To link to this article: http:// dx.doi.org/ 10.1080/00173139109427810

\section{PLEASE SCROLL DOWN FOR ARTICLE}

Taylor \& Francis makes every effort to ensure the accuracy of all the information (the "Content") contained in the publications on our platform. However, Taylor \& Francis, our agents, and our licensors make no representations or warranties whatsoever as to the accuracy, completeness, or suitability for any purpose of the Content. Any opinions and views expressed in this publication are the opinions and views of the authors, and are not the views of or endorsed by Taylor \& Francis. The accuracy of the Content should not be relied upon and should be independently verified with primary sources of information. Taylor and Francis shall not be liable for any losses, actions, claims, proceedings, demands, costs, expenses, damages, and other liabilities whatsoever or howsoever caused arising directly or indirectly in connection with, in relation to or arising out of the use of the Content.

This article may be used for research, teaching, and private study purposes. Any substantial or systematic reproduction, redistribution, reselling, loan, sub-licensing, systematic supply, or distribution in any form to anyone is expressly forbidden. Terms \& Conditions of access and use can be found at http://www.tandfonline.com/page/termsand-conditions 


\title{
A model to predict the beginning of the pollen season
}

\author{
TORBEN B. ANDERSEN
}

Andersen, T. B. 1991. A model to predict the beginning of the pollen season. - Grana 30: 269-275. 1991. Odense, September 1991. ISSN 0017-3134.

In order to predict the beginning of the pollen season, a model comprising the Utah phenoclimatography Chill Unit (CU) and ASYMCUR-Growing Degree Hour (GDH) submodels were used to predict the first bloom in Alnus, Ulmus and Betula. The model relates environmental temperatures to rest completion and bud development. As phenologic parameter 14 years of pollen counts were used. The observed dates for the beginning of the pollen scasons were defined from the pollen counts and compared with the model prediction. The CU and GDH submodels were used as:

1. A fixed day model, using only the GDH model with lst January as fixed initiation point.

2. A CU/GDH model, with a fixed sum of Chill Unit requirement as initiation point for the subsequent GDH accumulation.

3. A dynamic CU/GDH model, based on a dynamic relationship between $\mathrm{CU}$ and GDH. It is concluded that the $\mathrm{CU}$ and GDH relationships defined for fruit trees are generally applicable, and give a reasonable description of the growth processes of other trees. This type of model can therefore be of value in predicting the start of the pollen season. The predicted dates were generally within 3-5 days of the observed.

Finally the possibility of frost damage is discussed in relation to the great variation in the total pollen counts observed from one year to the other.

Torben Bo Andersen, Institute of Agricultural Sciences, Section of Horticulture, Royal Veterinary and Agricultural University, Bülowsvej 13, DK-1870 Frederiksberg C, Denmark.

Flowering is a phenological event, which is a result of a long period of development. The buds are initiated and differentiated into flower and vegetative buds during the summer. The falling temperatures of late summer causes a gradually change into a phase of winter rest with little or no growth activity. After a period, which in lenght apparently depends on the climate and the plant species, the plant gradually gocs back to a phase of active growth in the spring. The longer photoperiods and favorable temperatures finally causes the buds to break and flowers to emerge (Perry 1971, Vegis 1964):

The observed dates of first bloom, and thereby the beginning of the pollen season and pollen counts, are found to deviate profoundly from one year to another. In a 14 year period (1977 to 1990), the beginning of the pollen season in Denmark deviates within the following periods: Alnus - from the 30th December to the 1st April, Ulmus - from the 21th February to the 2nd May, and Betula - from 2nd April to the 9th May.

The determination of the end of rest and pre- diction of flowering has been the issue of several previous studies. In regard to fruit trees Ashcroft et al. (1977), Richardson et al. (1974), Richardson \& Anderson (1986) and Anderson \& Richardson (1986), have developed a phenoclimatography model which relates environmental temperatures to rest completion and bud development. Furthermore Winter (1986) correlated the phenologic development during the dormancy period with the evolution of frost resistance and simulated frost damage in apple trees. This strong correlation between the evolution of frost hardness and bud dormancy status has recently been verified by Colombo (1990).

Especially the buds and flowers are damaged by the frost which may reduce the fruit setting in fruit trees dramatically. Apparently the damage to the flowers affects both the amount of pollen despersed and the pollen germination. As both the time of season and the amount of pollen dispersed are of great interest in relation to pollen allergy, it would be very valuable if models similar to those proposed for fruittrees could be adapted to other trees. 
Table I. Betula Growing Degree Hours (GLH) accumulation from estimated end of rest to begin of flowering (2.5\% of total pollen count) for 7 estimates of Chill Unit $(C U)$ requirement.

Minimum standard deviation (SD) obtained at CU estimate 1900 giving an average of 2446 GDH.

\begin{tabular}{|c|c|c|c|c|c|c|c|}
\hline \multirow[b]{2}{*}{ Year } & \multicolumn{7}{|c|}{$\mathrm{CU}$} \\
\hline & 1700 & 1750 & 1800 & 1850 & 1900 & 1950 & 2000 \\
\hline 1977 & 2635 & 2568 & 2503 & 2364 & 2238 & 2167 & 1985 \\
\hline 1978 & 2762 & 2754 & 2736 & 2717 & 2694 & 2630 & 2571 \\
\hline 1979 & 2227 & 2167 & 2119 & 2043 & 1953 & 1720 & 1195 \\
\hline 1980 & 3155 & 3144 & 3053 & 2980 & 2932 & 2740 & 2649 \\
\hline 1981 & 2283 & 2277 & 2165 & 2095 & 2062 & 1828 & 1745 \\
\hline 1982 & 3074 & 2881 & 2490 & 2389 & 2023 & 1632 & 1424 \\
\hline 1983 & 2588 & 2538 & 2442 & 2377 & 2267 & 2215 & 2199 \\
\hline 1984 & 2594 & 2570 & 2555 & 2544 & 2459 & 2427 & 2216 \\
\hline 1985 & 2682 & 2670 & 2668 & 2646 & 2612 & 2543 & 2269 \\
\hline 1986 & 1394 & 1291 & 1216 & 1124 & 1043 & 979 & 900 \\
\hline 1987 & 2606 & 2576 & 2563 & 2550 & 2545 & 2536 & 2522 \\
\hline 1988 & 2276 & 2198 & 2145 & 2111 & 2078 & 2062 & 2052 \\
\hline 1989 & 3544 & 3449 & 3398 & 3356 & 3204 & 3119 & 3034 \\
\hline 1990 & 4637 & 4509 & 4425 & 4292 & 4136 & 3993 & 3922 \\
\hline & 712 & 699 & 696 & 691 & 682 & 697 & 741 \\
\hline Avg. GDH & 2747 & 2685 & 2606 & 2542 & 2446 & 2328 & 2192 \\
\hline
\end{tabular}

The aim of the present study was to test these phenoclimatographic models on the allergenic trees Alnus, Ulmus and Betula in order to provide a method to predict the beginning of the pollen season.

\section{METHODS}

Pollen counts have been practised in Denmark since 1977 with a Burkard Volumetric Spore Trap, placed 15 metres

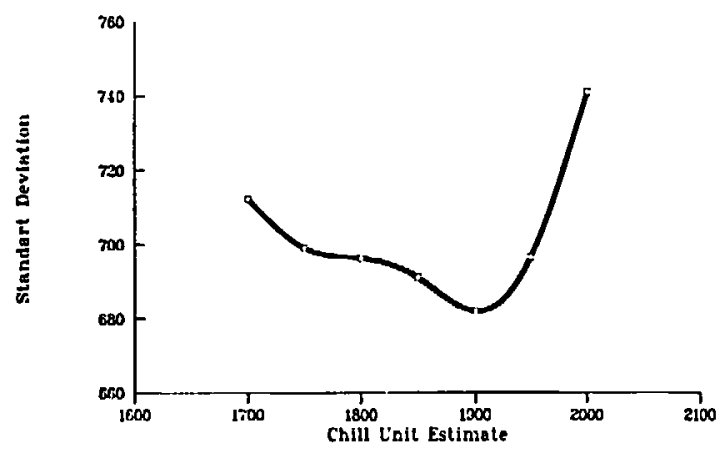

Fig. 1. Betula: Statistical estimation of Chill Unit (CU) and Growing Degree Hours (GDH) in the CU/GDH-model. Curve values $(\square)$ based on Table I. Minimum standard deviation obtained at CU estimate 1900. above ground, on the roof of the Danish Meteorological Institute in Copenhagen (Goldberg et al. 1988). As phenologic parameter in the model 14 years of pollen data from the trap were used. The start of pollen season was defind to be a fixed procent $(2.5 \%)$ of total counts. Furthermore hourly temperatures were estimated by the method of Linvill (1990), from 24-hours daily maximun and minimum temperatures, measured at Frederiksberg, Copenhagen.

Richardson et al. (1974), expressed the chilling requirement of fruit trees by Chill Units (CU). One CU defined as one hour at $6^{\circ} \mathrm{C}$, which was found to be the optimum Chill Unit temperature for fruit trees. This definition was applied in the present study.

The ordinary CU-model (Richardson et al. 1974) means the relation between the measured temperatures and the "Effective Bud Temperature". In order to simplify the calculations a sine function was used, as proposed by Linvill (1990). The initiation point for beginning of the CU calculations and accumulation was (as used by Richardson et al. 1974) determined to be the first day giving positive chilling values. The experimentally determined temperatures for the Growing Degree Hour (GDH) function (the base temperature $=4^{\circ} \mathrm{C}$, the optimum temperature $=25^{\circ} \mathrm{C}$ and the critical temperature $=36^{\circ} \mathrm{C}$ (Richardson \& Anderson 1986)) were used in this study for Alnus, Ulmus and Betula, except the base temperature which was changed to $2^{\circ} \mathrm{C}$, giving a slightly better correlation.

The chilling requirement and dates of rest completion were estimated with the statistical method developed by Ashcroft et al. (1977), minimizing the standard deviation of 
Table II. Total pollen counts, and observed dates of beginning of pollen season for Alnus, Ulmus and Betula. Start defined as $2.5 \%$ and $5 \%$ of total. Modelpredictions and deviation () in days from day nr. observed (Start def: $2.5 \%$ ).

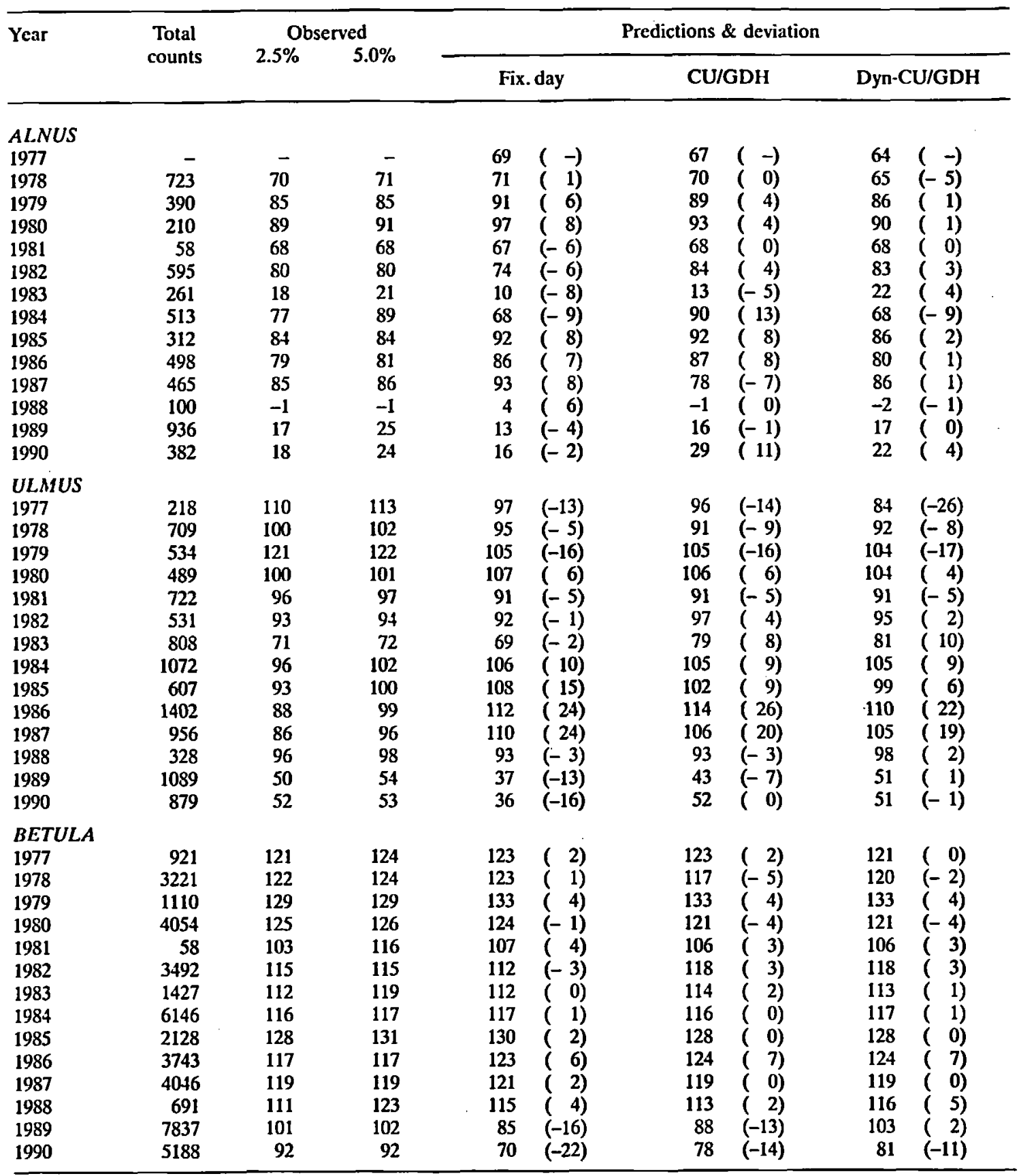

Growing Degree Hours (GDH) over a range of CU estimates. Exemplified in Table I, and Fig. 1 for Betula.

The ordinary (CU/GDH) model proposed by Richard- son et al. (1974) comprising the Chill Unit (CU) and the Growing Degree Hour (GDH) submodels, was compared to a simpler technique, a (Fix. day) model using only the 


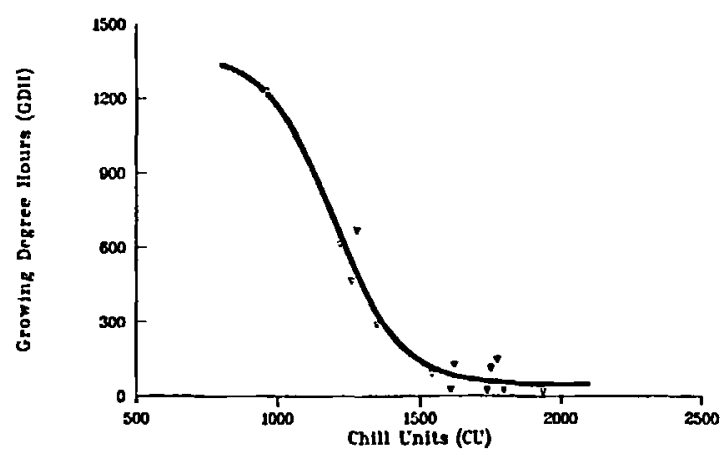

Fig. 2. The Growing Degree Hour requirement for Almis as a function of the accumulated amount of Chill Units. Values $(\nabla)$ and estimated curve based on Table III.

GDH submodel. 1st January was used as fixed initiation point.

A more complicated model involving the dynamic character of the dormancy growth fases was proposed. In this (Dyn-CU/GDH) model Chill Units were calculated and accumulated continuously during the winter. GDH-calculation was initiated every time the temperature rose above $2^{\circ} \mathrm{C}$. Every time the temperature fell below this level for more than 24 hours the GDH accumulation was reset to zero.

Winther (1986) expressed the frost hardness by a LT50 value defined as the temperature where $50 \%$ of the generative organs are killed. Based on the LT50 values experimentally determined by Winter, the LT50 value at budbreak was estimated for the present trees to be $-3^{\circ} \mathrm{C}$, and the "heighest" LT50 value reached in the dormant phase, corresponding the heighest level of dormancy, to be $-35^{\circ} \mathrm{C}$. A transformation of the dynamic CU/GDH function was used to estimate the frost hardness of the trees.

\section{RESULTS AND DISCUSSION}

The starting day depends on the definition chosen (Table II). Usually the starting dates obtained by different start definitions deviates 2-3 days, and in some years even 8-10 days. This uncertainty must be kept in mind when prediction models are compared.

The average Growing Degree Hours (GDH) accumulated from the ist January to the defined starting dates were: Alnus: 258 Ulmus: 1090 and Betula: 3000. The predicted dates are shown in Table II ("Fix. day" model).

In the ordinary Chill Unit and Growing Degree Hour model the CU and GDH requirement of the trees were statistically estimated to: Alnus: $\mathrm{CU}=$ $1550, \mathrm{GDH}=200$, Ulmus: $\mathrm{CU}=1850, \mathrm{GDH}=700$ and Betula: $\mathrm{CU}=1900, \mathrm{GDH}=2446$. Using these parameters, the predicted dates for the beginning of the season were determined, (Table II, "CU/GDH" model.

In the dynamic model the corresponding $\mathrm{CU}$ and GDH values until the start of the season were determined by the procedure described. Using this method neither the CU nor the GDH was fixed, but the necessary GDH to budbreak was adjusted according to the amount of Chill Units obtained. As can be seen in Table III the Chill Units and Growing Degree Hours obtained deviated from one year to the other according to the different temperature regimes observed. The relationship between $\mathrm{CU}$ and GDH was proposed to follow a not-lineary function, with shape of an s-curve as illustrated in Fig. 2. for Alnus:

$$
\mathrm{GDH}=\mathrm{C}+(\mathrm{D}-\mathrm{C}) / 1+\operatorname{EXP}\left(\left(\mathrm{CU}-\mathrm{CU}_{\mathrm{o}}\right) / \mathrm{A}\right)
$$

GDH: Growing Degree Hour requirement to flowering.

C: Minimum number of GDH's required.

D: Maximum number of GDH's required.

CU: Chill Units obtained.

$\mathrm{CU}_{0}$ : The inflexion point, (at which the fall in GDH requirement are fastest.

A: The slope of the curve at the inflexion point.

The parameters were estimated by non-linear regression (NLIN) using SAS/PC (Statistical Analysis System for Personal Computers), (Table III). Finally the dates were predicted (Table II "Dyn-CU/GDH" model).

When compared with the observed dates the predictions made by the simple "Fix-day" model are within 4-8 days for Alnus, more than 10 days for Ulmus and Betula 5-7 days. Using the CU/GDH model the predictions are about the same for Alnus

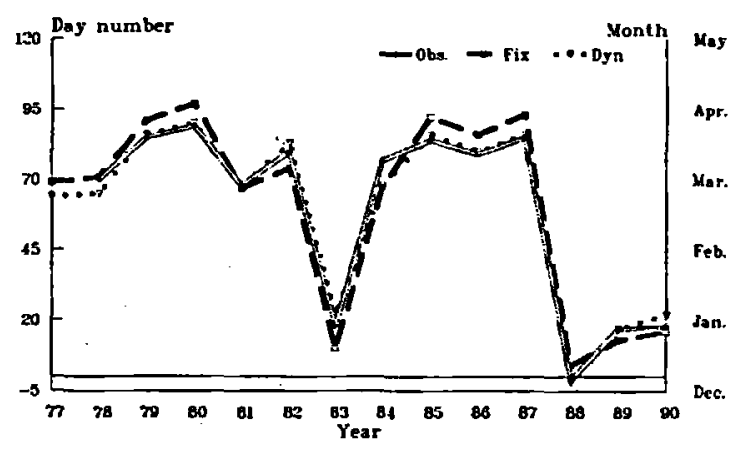

Fig. 3. Observed dates for beginning of the Alnus pollen season compared with model predictions. Based on Table II (Day nr $1=>1 / 1$, nr $0=>31 / 12$ and $n r-5=>26 / 12$ ). 
Table III. Chill Units (CU) and correspondin Growing Degree Hours (GDH) determined by the dynamic model, and estimated model parameters in the function:

$\mathrm{GDH}=\mathrm{C}+(\mathrm{D}-\mathrm{C}) / 1+\exp \left(\left(\mathrm{CU}-\mathrm{CU}_{\mathrm{o}}\right) / \mathrm{A}\right)$

GDH : Growing Degree Hour requirement to flowering.

C : Minimum number of GDH's required.

D : Maximum number of GDH's required.

$\mathrm{CU}$ : Chill Units obtained.

$\mathrm{CU}_{4}:$ The inflexion point, (at which the fall in GDH requirement are fastest).

A : The slope of the curve at the inflexion point.

\begin{tabular}{|c|c|c|c|c|c|c|}
\hline \multirow[t]{2}{*}{ Year } & \multicolumn{2}{|c|}{ ALNUS } & \multicolumn{2}{|c|}{ ULMTUS } & \multicolumn{2}{|c|}{$B E T U L A$} \\
\hline & $\mathrm{CU}$ & GDH & $\mathrm{CU}$ & GDH & $\mathrm{CU}$ & GDH \\
\hline 1977 & - & - & 1695 & 1361 & 1695 & 2641 \\
\hline 1978 & 1776 & 146 & 2106 & 1094 & 2106 & 2465 \\
\hline 1979 & 1608 & 27 & 1608 & 1882 & 1608 & 2351 \\
\hline 1980 & 1740 & 21 & 1740 & 427 & 1740 & 3148 \\
\hline 1981 & 1754 & 111 & 1858 & 1121 & 1858 & 2090 \\
\hline 1982 & 1352 & 291 & 1352 & 1232 & 1352 & 3388 \\
\hline 1983 & 1219 & 612 & 2030 & 296 & 2030 & 2193 \\
\hline 1984 & 1622 & 127 & 1622 & 301 & 1622 & 2685 \\
\hline 1985 & 1800 & 23 & 1800 & 294 & 1800 & 2668 \\
\hline 1986 & 1541 & 91 & 1541 & 308 & 1541 & 1599 \\
\hline 1987 & 1938 & 18 & 1938 & 58 & 1938 & 2540 \\
\hline 1988 & 1279 & 669 & 2511 & 470 & 2511 & 1759 \\
\hline 1989 & 959 & 1228 & 959 & 2317 & 959 & 4820 \\
\hline 1990 & 1260 & 464 & 1260 & 1882 & 1260 & 5440 \\
\hline C : & & 46 & & 565 & & 2262 \\
\hline D : & & 1384 & & 2590 & & 5473 \\
\hline $\mathrm{CU}_{\mathrm{o}}:$ & & 1198 & & 1292 & & 1332 \\
\hline A : & & 120 & & 166 & & 179 \\
\hline
\end{tabular}

and Ulmus but slightly improved to be within 4-6 days for Betula.

Compared to these two models the predictions are improved to be within 2-4 days for Almus, 8-10 days for Ulmus and 3-5 days for Betula in "the DynamicCU/GDH model" (Table II and Fig. 3).

A deviation of this size must be regarded as acceptable compared both to the very large deviation in time form one year to the other (about 4 months for Alnus), and the uncertainity in the definition of starting dates. Though it must be a question of priority between a simple model with predictions within a reasonable deviation or a more complicated model, and a slightly better prediction.

If the predictions are to be further improved a photoperiodic parameter apparently has to be included, especially in regard to Ulmus and Betula. From 1st March to 1st May the daylength in Den- mark increases about five hours, from about ten hours to fifteen hours. This marked increase obviously plays a role in relation to the budbreak.

The buds of Betula detect the day length directly, apparently the bud scales themselves respond, or enough light penetrates to bring about the respons within the primordial leaf tissues inside the bud ( $\mathrm{Sa}$ lisbury \& Ross 1985).

The involvement of a dynamic relationship complicates the model a little, but tends to improve the simulation of the gradual changes during dormancy and budbreak. The s-formed relationship shown in Fig. 2 for Alnus is consistent with the descriptions of several authors (Perry 1971, Vegis 1964). According to Perry (1971) and Vegis (1964) the level of dormancy changes very much during winter giving it a normal distribution or "bellshaped" character.

The level of dormancy and heat required to break dormancy gradually increases during autumn, and then the process is reversed in spring. The same results were found by Swartz \& Powell (1981), Borkowska (1981) and Crabbé (1981): long chilling treatment increased the growthability and lowered the heat requirement.

The relationship found by the "dynamic model" also fits very well with the chilling requirement estimated by the ordinary Chill Unit and Growing Degree Hour model: at 1550 Chill Units (CU requirements for Alnus) the fall in heat (GDH) requirement is no longer significant.

By using the LT50 submodel, days where frost

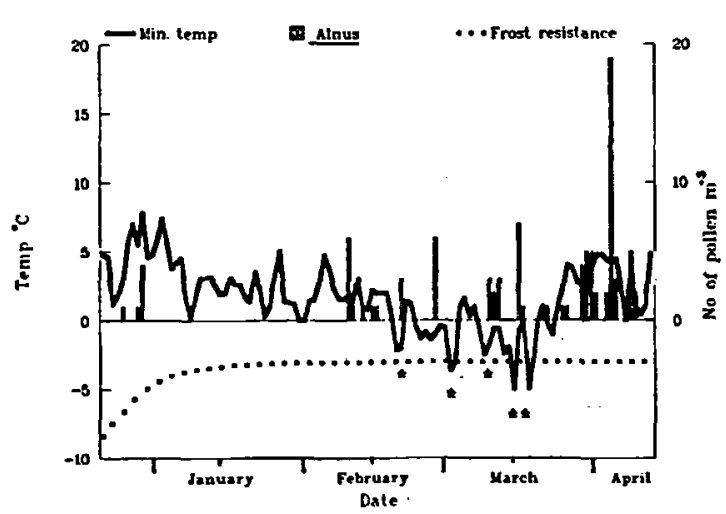

Fig. 4. The climate in the spring 1988 , and the Aluus pollen season. The pollen counts were not started before the 8 . February but as the model predicted it to start before new year control counts were made and Alnus pollen were found! Later on lethal temperatures $\left({ }^{*}\right)$ caused severe damage. 


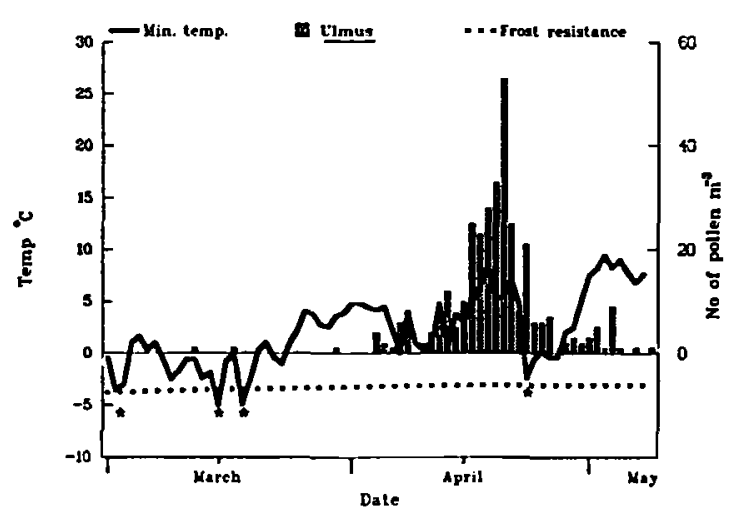

Fig. 5. The climate in the spring 1988, and the Ulmus pollen scason. Frost damage apparently occured both before and in the season $\left(^{*}\right)$.

damaged might have occured were detected, especially in 1981 and 1988 (Figs. 4 and 5) - though the exact level of the LT50 values have to be confirmed by experiments with Alnus, Ulmus and Betula. These damages give a reasonable answer to the question why so few pollen grains were found in 1981 and 1988 (Table II). If the hormonal regulation mechanisms, known to control alternate bearing in apples (Lavee 1989), are applied to the present trees it can explain the biennial tendency observed in the pollen seasons.

In apple trees the developing fruits produces hormones, mainly gibberellines and auxins, which reduces the flower bud development the following year, i.e., years with a great pollination and fruitdevelopment give a high hormonal production giving few flowers and pollen grains next year, - and years with poor pollination and fruiting, give many pollen grains in the following year.

Very often it is an environmental factor which induces this cycle. Severe frost damage (or drought) could be the one. The potential production of pollen apparently depends on the climate during bud development and differentiation in the summer, but the actual amount dispersed and observed is very much dependent on the weather during budbreak and flowering. In other words frost damage might affect both total pollen counts in the actual year and the potential pollen amount the following year. This makes predictions of the total counts very difficult.

\section{CONCLUSION}

The predictions obtained by the models must be regarded as acceptabel in relation to the many uncertainties involved with weather prediction, pollen dispersal and pollen monitoring. Alnus tends to be completely regulated by the temperature while other parameters like the photoperiod apparently has to be involved in relation to Ulmus and Betula if predictions are to be further improved.

The CU and GDH relationships defined for fruit trees are generally applicable, giving a reasonable description of the growth processes for other trees. This type of model can therefore be of value in predicting the start of the pollen season. Furthermore the results indicate that frost damage might be an important factor which can strongly affect the total pollen counts.

\section{REFERENCES}

Anderson, J. L. \& Richardson, E. A. 1986. Validation of Chill Unit and flowerbud phenology models for "Montmorency" sour cherry. - Acta Hortic. 184. [Modelling in Fruit Rescarch.]: 71-78.

Ashcroft, G. L., Richardson, E. A. \& Seeley, Schuyler D. 1977. A statistical method of determining chill unit and growing degree hour requirements for deciduous fruit trees. - Hortic. Sci. 12: 347-348.

Borkowska, B. 1981. Dormancy and development of apple axillary buds investigated in vitro. - Acta Hortic. 120 [Growth regulators in Fruit Production]: 161-166.

Colombo, S. J. 1990. Bud dormancy status, frost hardiness, shoot moisture content, and readiness of black spruce container seedlings for frozen storage. J. Am. Soc. Hortic. Sci. 115: 302-307.

Crabbé, J. J. 1981. The interference of bud dormancy in the morphogensis of trees and shrubs. - Acta Hortic. 120 [Growth regulators in Fruit Production]: 167-172.

Goldberg, C., Buch, H., Moseholm, L. \& Weeke, E. R. 1988. Airborne pollen records in Denmark, 1977-1986. - Grana 27: 209-217.

Lavee, S. 1989. Involvement of plant growth regulators and endogenous growth substances in the control of alternate bearing. - Acta Hortic. 239. [Growth regulators in Fruit Production]: 311-322.

Linwill, D. E. 1990. Calculating Chilling Hours and Chill Units from Daily Maximum and Minimum Temperature Observations. - HortScience 25: 14-16.

Perry, T. O. 1971. Dormancy of trees in winter. - Science. 171: $29-36$.

Richardson, E. A. \& Anderson, J. L. 1986. The omnidata biophenometer (TA45-p): A Chill Unit and Growing Degree Hour Accumulator. Acta Hortic. 184 [Modelling in Fruit Research.]: 95-99.

Richgrdson, E, A., Seeley, Schuyler D. \& Walker, D. R. 
1974. A model for estimating the completion of Rest for "Redhaven" and "Elberta" Peach Trees. - HortScience. 9: 331-332.

Salisbury, F. B. \& Ross, C. W. 1985. Plant physiology, 3rd ed. - Wattsworld Publ. Co., Bellmond, California.

Swartz, H. J. \& Powell, L. E. Jr. 1981. The effekt of long chillingrequirement on time of bud break in apple. Acta Hortic. 120. [Growth regulators in fruit production.]: 173-178.

Vegis, A. 1964. Dormancy in higher plants. - Ann. Rev. Plant Physiol. 15: 185-224.

Winter, F. 1986. A simulation model of phenology and corresponding frost resistance of "Golden Delicious" apple. - Acta Hortic. 184 [Modelling in Fruit Research]: 103-108. 